\title{
A CULTURA DE CORDEL NAS RUAS, NAS FEIRAS E NA ACADEMIA
}

Yvone Dias Avelino*

A literatura de cordel é uma das manifestações populares mais ricas da cultura brasileira. É muito comum nas regiões Norte e Nordeste do país, especialmente nos Estados do Pará, Pernambuco, Rio Grande do Norte, Alagoas, Paraíba e Ceará.

Suas origens são europeias, onde, na península Ibérica era chamada de "pliegos" e "sueltos", ou seja, folhas soltas e volantes, especialmente em Madrid e Barcelona; especificamente em Portugal, era conhecida como literatura de cegos, a qual passou a ser uma lei promulgada por D. João V, que permitiu que a Irmandade dos Homens Cegos de Lisboa pudesse trabalhar publicizando nas calçadas de igrejas. Até então era considerada ociosidade.

Nos séculos VIII e IX d.C. já existia na França, como folhetos chamados "colportage" e "cannards" e a "biblioteca azul". Isso de acordo com estudo feito por Robert Mandrou de cultura popular que lidava com a literatura em Troyes, Lyon e Bordeaux, na região Nordeste da França. ${ }^{1}$

No Brasil, a literatura de cordel tem suas raízes no Nordeste brasileiro, ganhando espaço no século XIX, mas adquiriu maior força e popularidade entre as décadas de 1930 e 1960, sendo marcada por fortes elementos da cultura brasileira. Trata-se de uma crônica popular que relata os eventos regionais em forma de poesia, expressando a cosmovisão da população por meio de uma linguagem simples e em forma de versos. Busca informar os leitores utilizando recursos alegres, divertidos e forte oralidade. É uma tradição regional, ao contrário da literatura convencional. Chegou ao Brasil com os colonizadores portugueses e se enraizou no Nordeste; conforme afirma o poeta Marco Haurélio, um dos pioneiros do cordel no Brasil foi Silvino Piruá de Lima 1848-1913) e depois Leandro Gomes de Barros (1868-1919). ${ }^{2}$ Nasceu e morreu em seu estado, a Paraíba, e viveu escrevendo versos populares, assim como vendendo e

\footnotetext{
* Titular no Departamento de História, da Pontifícia Universidade Católica de São Paulo. Mestrado em História Social pela Universidade de São Paulo, Doutorado em História Econômica pela Universidade de São Paulo e PósDoutorado (1989) em História pela PUC-SP. Integra as Comissões Consultivas e Editorias das seguintes Revistas: Oralidades - Revista de História Oral (USP); Práxis - Revista Eletrônica de História e Educação (Universidade Jorge Amado - Salvador); Projeto História (PUC-SP); Aurora - Revista Eletrônica de Arte, Mídia e Política (PUC-SP). Atua principalmente nos seguintes temas: Cidade, Cultura, História, Memória, Literatura e América Latina. Coordena o Núcleo de Estudos de História Social da Cidade - NEHSC - PUC-SP, existente há mais de 27 anos. Coordenou o curso de graduação em História da PUC-SP. É Editora da Revista Cordis - Revista Eletrônica de História Social da Cidade (http://revistas.pucsp.br/cordis). Email: yvonediasavelino@uol.com.br

${ }^{1}$ BURKE, P. A Escola dos Annales (1929-1989). São Paulo: UNESP, 2011, p. 91-92.

${ }^{2}$ CASCUDO, L. C. Vaqueiros e Cantadores. São Paulo: Global, 2005. p.26.
} 
declamando por todo o interior do Nordeste. É considerado um dos mais lidos pelos escritores populares e o mais fecundo de todos, pois chegou a publicar mais de mil folhetos cordelianos.

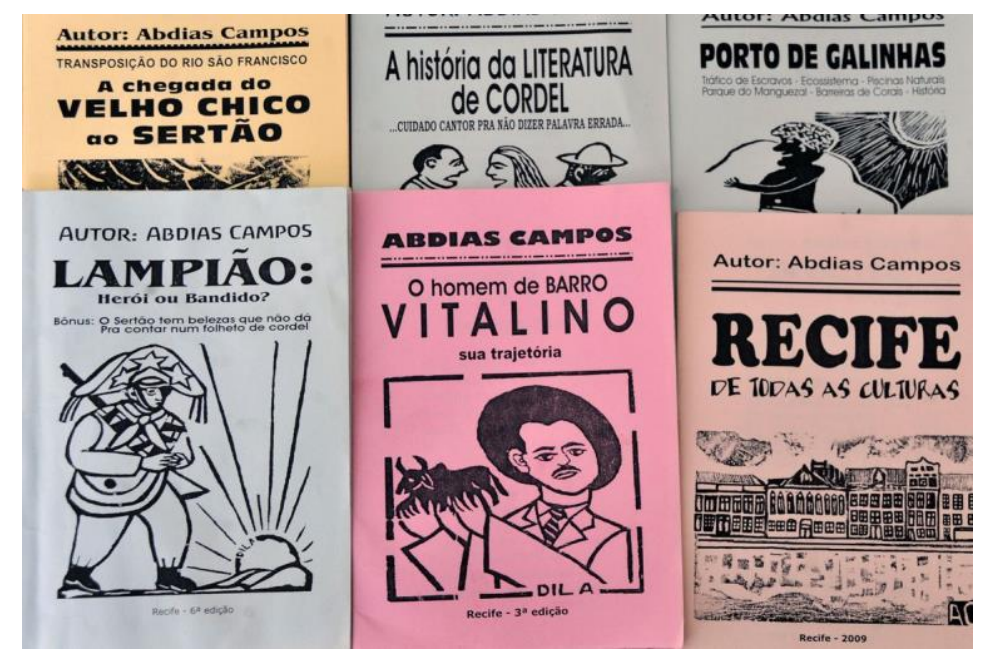

Figura 1: Cordéis expostos.

De uma maneira geral, essa literatura é apresentada em formato de pequenos livros com capa de xilogravura, que ficam pendurados em cordas, ou cordéis (barbantes), daí a origem do seu nome. Ficam pendurados para secar e para serem vendidos a preços bem populares e são seus autores que divulgam suas próprias obras.

A literatura de cordel consiste em um gênero literário elaborado em versos e com linguagem popular retratando temas do cotidiano. No que se refere ao conteúdo, tem como caraterísticas principais o uso do humor, da ironia, do sarcasmo, uma linguagem coloquial bem informal, uma intensa presença da oralidade em rimas e métricas e abordagem de diversos temas: sociais, históricos, folclóricos, religiosos e políticos. Essa cultura consegue despertar atualmente o interesse de novos poetas cordelistas por meio de oficinas e eventos e o grande desejo de aprender uma outra modalidade poética.

A literatura de cordel está cada dia mais se modernizando e com o processo migratório se desenvolve também na cidade de São Paulo, sem fugir de suas formas tradicionais, de suas raízes, mas com inovações nos seus temas, saindo de modestas feiras no bairro do Brás, para novos espaços, como bibliotecas, casas de cultura e na mídia paulistana. Os poetas deixaram de pendurar os seus folhetos em cordões nas feiras para os deixarem em exposição nos lugares onde realmente devem estar, que são as casas de cultura, escolas, bibliotecas e livrarias.

Em 1988, com o objetivo de resgatar, manter a memória e a importância cultural do cordel, no mês de setembro foi criada a Academia Brasileira de Literatura de Cordel, que possui 
mais de nove mil documentos contendo livros, folhetos de cordel e pesquisas sobre os mais diversos aspectos desse tipo de literatura oferecendo amplo apoio aos autores e tendo já dois mil digitalizados.

Grandes, competentes e famosos escritores brasileiros, influenciados por esse tipo de literatura, tiveram seus traços notados em suas principais obras, como Guimarães Rosas, em Grande Sertão Veredas, Ariano Suassuna, em O Auto da Compadecida, João Cabral de Melo Neto, em Morte e Vida Severina, e José Lins do Rego, em Riacho Doce.

Há vários cordelistas com as obras mais significativas no Brasil, sendo considerados os "mestres do cordel".

Entre tantos, aponto um dos primeiros, que data do período imperial, João Martins de Athayde, e outro mais contemporâneo, um jovem autor que vem ganhando cada vez mais notoriedade, em virtude de sua habilidade e competência com essa literatura. Trata-se de Bráulio Bessa, poeta, declamador e palestrante que tem uma participação semanal em importante programa da mídia televisiva brasileira.

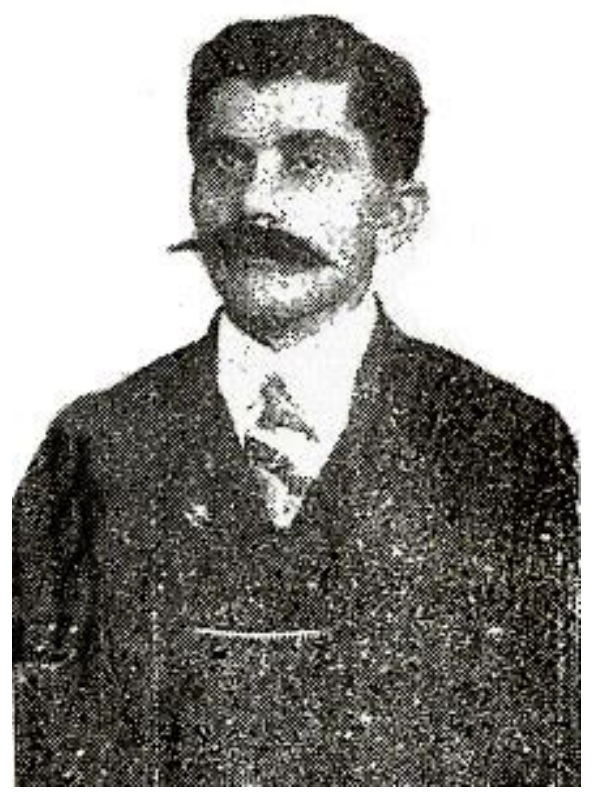

Figura 2 João Martins de Athayde

No século XIX surgiram os primeiros mestres dessa literatura, tais como Leandro Gomes de Barros e Germano Lagoa. O trabalho dos vendedores de folhetos foi determinante para a disseminação dessa literatura, sendo a divulgação feita em feiras.

Atualmente a literatura de cordel vive um momento de reflorescimento, após inúmeras transformações de produção e circulação ocorridas ao longo do século XX, chegando mesmo a ter sua morte anunciada por estudiosos e autores no final da década de 80. Desde os anos 2000, 
no entanto, vem encontrando formas de sobrevivência em novos formatos, com outros públicos, chegando a ser objeto de atenção na academia.

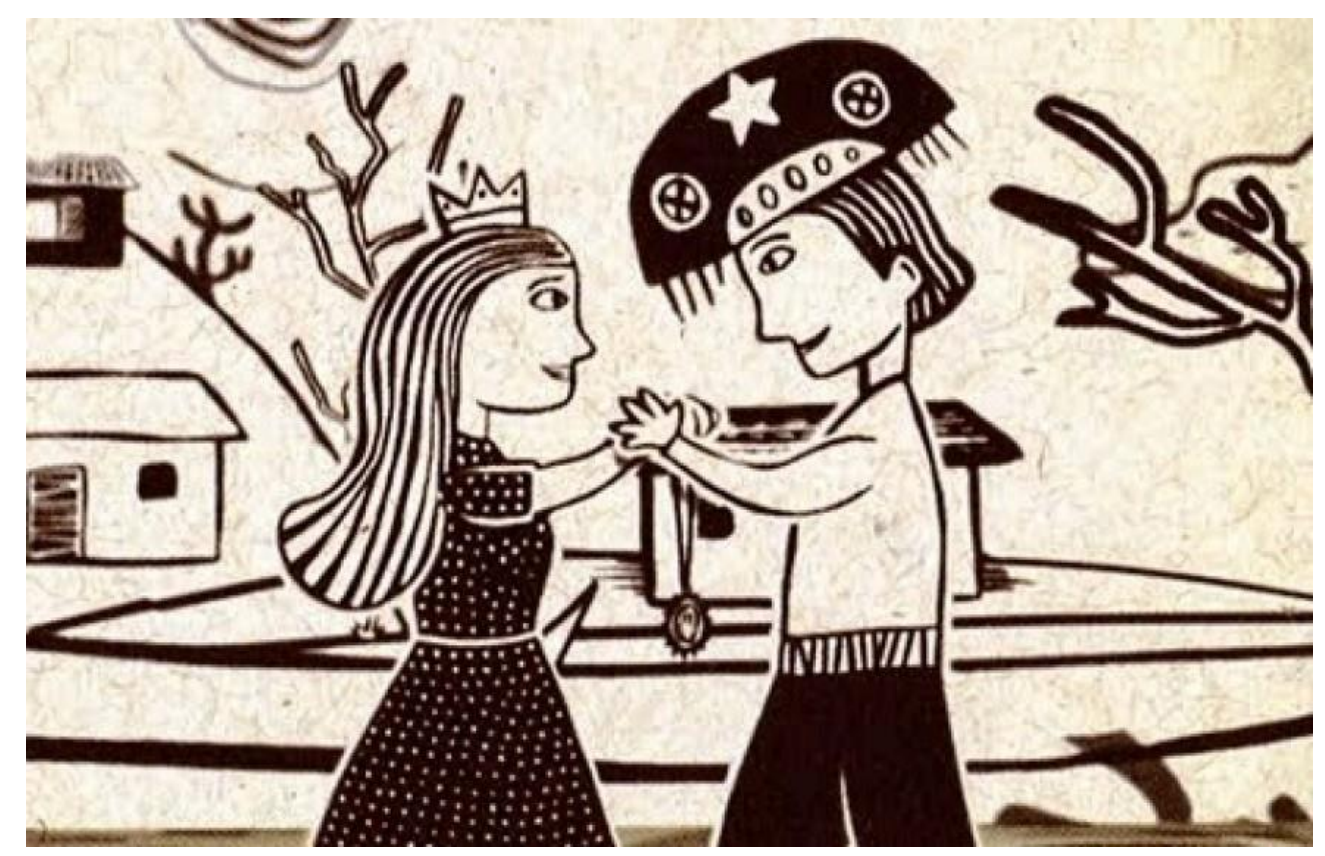

Figura 3 Trecho da abertura da novela Cordel Encantado. Rede Globo

Seu reconhecimento mais recente foi a criação do Patrimônio Cultural Imaterial Brasileiro pelo Instituto do Patrimônio Histórico e Artístico Nacional (IPHAN), que coloca no horizonte da sociedade e do Estado a necessidade de estratégias para proteger a produção e atuação desses poetas cordelistas.

Um dos exemplos estudados na academia é o do professor Francisco Claudio Alves Marques, da Faculdade de Ciências e Letras da Universidade Estadual Paulista (UNESP), campus de Assis, onde, na sua obra Escritos e Ditos: Poéticas e Arquétipos da Literatura de Folhetos Itália/Brasil Humanitas (no prelo), afirma: “A poesia de cordel nordestina apresenta traços de uma produção escrita anterior, que vem se juntar à oralidade fortemente presente na região", apontando as principais fontes que inspiraram cantadores e poetas populares, além de histórias comuns da Península Ibérica, fábulas, passagens bíblicas reunidas em almanaques e enciclopédias.

Segundo o autor, ao contrário do que se pensa, essa literatura não depende apenas da capacidade de improvisação, mas como adaptam o repertório literário já existente, como vozes e mãos de narrativas ancestrais. Um dos exemplos estudados por Marques é o "mito da coconha", cultura popular europeia do século XIII. 
Outro acadêmico que estuda e tem interesse nessa literatura é o historiador Paulo Teixeira Iumatti, vice-diretor, entre 2014 e 2018, do IEB-USP, com a publicação Vozes Negras na Cantoria: Cantadores afrodescendentes e as disputas em torno do gênero do marco (18701930) Almedina.

A historiadora Rosilene Alves de Melo, da Universidade Federal de Campina Grande na Paraíba, afirma que, embora se trate de uma literatura originada em contextos pobres, "A literatura de cordel nunca foi reconhecida pelo universo da literatura oficial, embora muitos poetas e escritores fossem seus admiradores. A literatura de cordel sempre fez a mediação entre universos: um mais letrado e outro da cultura oral, como uma poesia que chegava às pessoas que nem sequer sabiam ler."

A literatura de cordel teve, em São Paulo, uma grande influência por meio dos migrantes, pois sua capital é considerada a mais nordestina do Brasil e a sua historicidade faz parte de uma relação ativa no cotidiano paulistano. É uma manifestação que se faz presente e que se alinha com o contexto social dessa cultura popular e da expansão geográfica periférica na cidade de São Paulo.

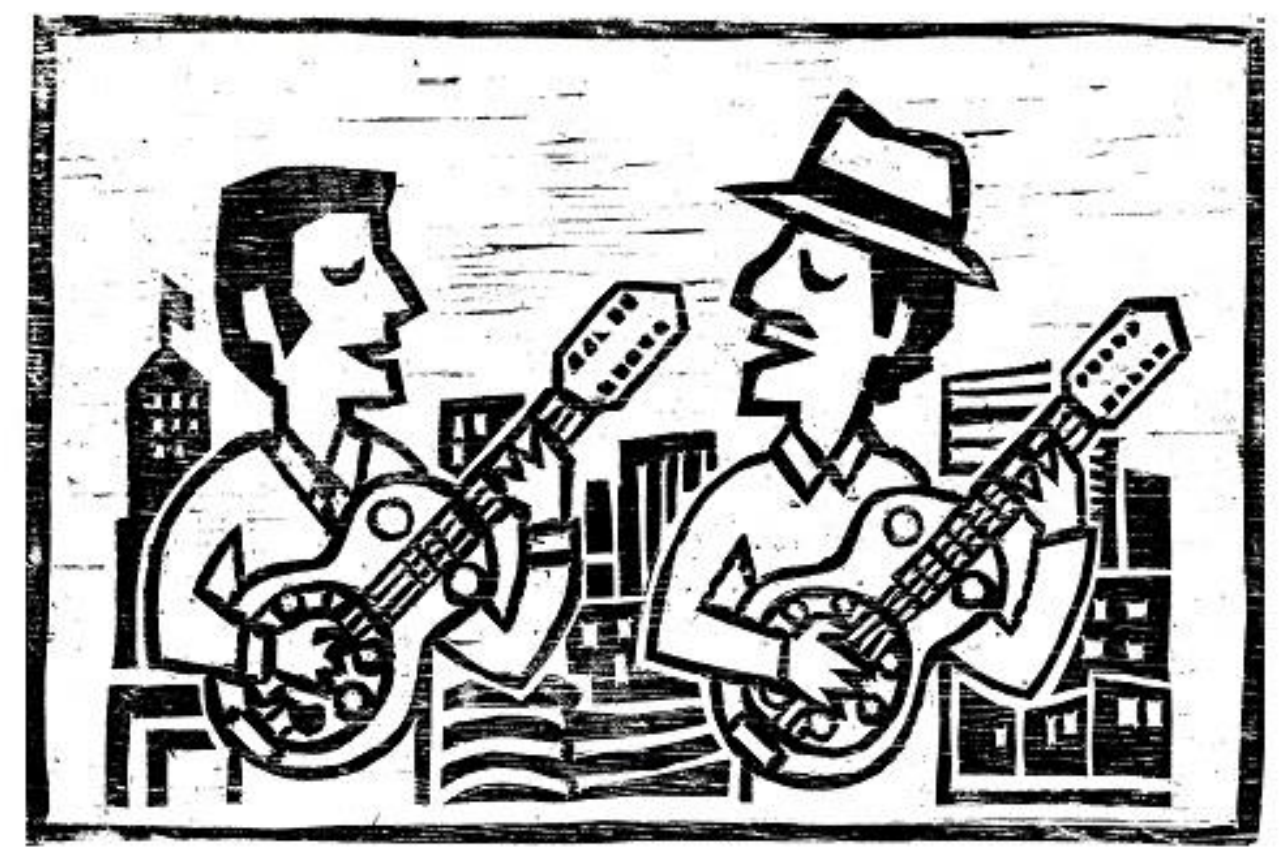

Figura 4: O cordel na cidade de São Paulo

Podemos ressaltar que esses autores têm diferentes formações e, entre eles, encontramos advogados, historiadores, administradores, educadores, pedagogos e psicólogos. Percebe-se que esses diferentes níveis de escolaridade não mudam em nada a forma de compor a literatura 
de cordel, ou seja, nordestinos, paulistanos ou paulistas, esses poetas mantêm a mesma tradição cultural de seus antecedentes, carregando suas manifestações, trazendo algumas inclusões poéticas regionais motivadas por costumes que nasceram em outra região.

A literatura de cordel está cada dia mais se expandindo na capital paulista, pois é comum ser transmitida diariamente nas rádios dessa imensa metrópole, na Band FM e na Rádio Imprensa FM. Nessa cidade, os poetas não penduram mais seus folhetos em cordéis nas feiras, mas encontram lugares específicos onde são feitas exposições nessa imensa megalópole, desde escolas, livrarias, bibliotecas etc.

Os poetas de cordel saíram do anonimato para integrarem os centros dos grandes acontecimentos onde encontram várias editoras interessadas em seus trabalhos como Luzeiro, Cortez, Hedra etc., tornando-se um campo farto para pesquisadores e amantes da cultura popular; aí são vendidos folhetos, livros, CDs e DVDs, que são encontrados em vários lugares da cidade de São Paulo, nas mesmas prateleiras onde se podem encontrar Luís da Câmara Cascudo, Leonardo Mota, Silvio Romero e tantos outros escritores famosos.

O professor e pesquisador Joseph M. Luyten afirma: "a cultura popular se dá em sociedades em que a elite e o povo participam de manifestações comuns, como língua, religião, composição étnica, assim por diante". As manifestações populares sempre se darão, em sua grande maioria, de forma oral. Assim sendo, a literatura de cordel deixou de ser um simples jornal informativo nos rincões sertanejos do Nordeste, na penumbra de uma luz de um velho candeeiro ou nos antigos lampiões a gás para brilhar com as lâmpadas modernas nos grandes centros urbanos como aconteceu em 2001, no Sesc Itaquera, expandindo-se por universidades, escolas públicas e privadas.

A literatura de cordel não está só guardada em pequenos folhetos ou livros para pesquisadores em bibliotecas, livrarias ou museus, ela está presente sobretudo na oralidade de seus cordelistas, com suas vozes agudas e no malabarismo da recitação de seus poetas (LUYTEN, 2005, p. 24).

São inúmeros saraus que acontecem em toda a grande São Paulo, em locais que lotam com a presença de admiradores e seguidores dessa cultura popular, onde se admiram os versos dos poetas, sua fluidez e precisão, transmitindo uma energia fervilhante onde as cenas vivas demonstram a história de um passado distante trazido para o presente por meio de uma imaginação lúcida e versada, onde a oralidade se torna escrita, mesmo tendo se desenvolvido num impulso de um improviso falado, passando de boca em boca, vindo de gerações passadas para gerações atuais. Alguns pesquisadores, como o jornalista Assis Ângelo, afirmam: “os cordelistas são poetas de bancadas porque normalmente escrevem suas estrofes sentados sobre 
uma mesa com sua caneta em punho como são os verdadeiros poetas pensantes, escrevendo em versos suas histórias embaladas pelos acontecimentos dessa metrópole encantadora, onde estes encantam no desabrochar de cada estrofe, no sopapo de suas combinações de rima". (ASSIS, 2007, p. 2)

Vários folhetos de cordéis são escritos totalmente anônimos, ou seja, são folhetos feitos por alguma gráfica, mas sem editora e sem registro em nenhum órgão autorizado para uma possível reclamação dos direitos autorais. São cordelistas sem condições financeiras que nomeiam o folheto com seu nome, lugar e título e, no final, deixam o endereço para possíveis contatos. Esses jograis contemporâneos, cheios de inovações arrojadas para soltarem suas poesias críticas, são, segundo o pesquisador Joseph M. Luyten (2005, p. 11): “o principal motivo de as sociedades humanas, quando são iletradas, têm a memória como único recurso para guardar o que acham importantes, daí a tendência de ordenar toda espécie de mensagens em forma poética." (LUYTEN, 2005, p. 11).

Podemos afirmar, sem nenhum equívoco, que a literatura de cordel é um marco essencial de resistência da cultura popular, pois a forma como esses poetas mantêm sua tradição em interpretações escritas, em forma de rimas cuidadosa e milimetricamente compostas nas estrofes, em cada verso onde estas linhas não faltam nem sobram há sempre uma possível colocação musical presente ou a possibilidade de uma futura gravação desse poema. $\mathrm{O}$ interessante é que os folhetos feitos na cidade de São Paulo seguem os mesmos padrões tradicionais do Nordeste e já existem artistas em xilogravura nascidos aqui e fazendo as ilustrações desses folhetos.

Cada poeta apresenta-se a seu modo, ao seu estilo. Há poetas que brincam, encenando uma interpretação como se fosse um artista de teatro. Ele circula entre os apreciadores com sua oralidade, promovendo risos, palmas, admirações e driblando muitas vezes suas próprias ilusões. Existe assim cordelista que faz questão desse antagonismo, ou seja, não faz questão de fazer outra poesia a não ser a própria do cordel. Seguem firmes e opostos a qualquer outro tipo de poesia.

Esses cordelistas obedecem à sua gesta e a suas estruturas poéticas, mantendo as tradições e uma conexão entre elas, com a sua voz integrando-se em um bailado de palavras coloquiais e bem rimadas por algum tempo. Alguns se atrevem a citar algumas estrofes de improviso, ao meio de uma roda de sarau e ouvintes, esquecendo a caneta por alguns instantes, no impulso efervescente da poesia, mas isso é uma rara passagem entre eles.

Os cordelistas têm uma voz que tem uma espécie de timbre que é todo seu, que vai passando a sua cumplicidade poética para aquela coletividade presente em cada lugar. Os 
presentes ficam de olhos arregalados e atenção para aquela recitação e ninguém quer perder um segundo, parece que o público daquele local fica encantado em uma metamorfose de versos e palavras e os poetas vão reinventando uma epopeia de poesias e desfigurando a geografia de suas poesias naquele instante. Sem distorcer a sua construção discursiva, a intenção de qualquer poeta cordelista é mostrar o seu argumento literário com uma precisão de rima e de originalidade natural.

Portanto, discorrer sobre o estudo da literatura de cordel é realmente uma temática difícil de ser analisada por existir nela uma variedade de definições e uma dupla visão do tipo de poeta, pois ora ele é um artista, ora ele é um comentarista da vida cotidiana em versos.

O poeta leva consigo mesmo uma íntima relação com seu público leitor e seguidor dessa poesia popular, mantendo os seus domínios literários, passando um argumento discursivo em forma de poesia com uma única técnica oral sem par ou ímpar que só existe na literatura popular de cordel.

Se o trabalho dos vendedores de folhetos foi determinante para a disseminação desse tipo de literatura, sendo a divulgação amplamente realizada em feiras, pequenas cidades e lugarejos do interior do Nordeste, atualmente os meios de comunicação diminuíram a popularidade desse tipo de literatura, havendo um movimento artístico no sentido de manter vivas as características e a importância dessa escrita, já que ela consiste em uma parte fundamental da cultura brasileira, ou seja, a literatura de cordel foi assumida pela intelectualidade nacional, penetrando as universidades como Amazonas, Campina Grande, na Paraíba, e a Universidade de São Paulo, onde competentes especialistas estudam e divulgam a literatura de cordel. Na PUC/São Paulo, essa literatura foi competentemente divulgada pela Professora Doutora Jerusa Pires Ferreira, infelizmente recentemente falecida, que dedicou sua vida a assuntos importantes, entre eles a literatura de cordel. No livro "Cavalaria em cordel: o passo das águas mortas", a autora traz à cena a cavalaria medieval, com a apresentação de um estudo específico de seus ciclos narrativos em prosa e verso que vão da gesta, do poema épico, ao poema de encantamento, trazendo uma relação com o cordel. (FERREIRA, 2006).

Mostra da importância deste gênero literário para a cidade de Sã Paulo é que uma de suas mais tradicionais bibliotecas, a Mário de Andrade, reserva um espaço específico para seu acervo sobre literatura de cordel. 


\section{REFERÊNCIAS BIBLIOGRÁFICAS}

ASSIS, A. Revista Cultura Crítica, São Paulo, p. 2, jul./dez. 2007.

ASSIS, A. Dicionário Gonzaguiano de A a Z. São Paulo: Parma, 2006.

BURKE, P. A Escola dos Annales (1929-1989). São Paulo: UNESP, 2011.

CASCUDO, L. C. Vaqueiros e Cantadores. São Paulo: Global, 2005.

CHARTIER, R. A História Cultural: entre práticas e representações. Lisboa: Difel, 1990.

FERREIRA, J. P. Cavalaria em Cordel: O Passo das águas mortas. São Paulo: Edusp, 2006.

LUYTEN, J. L. O Que é Literatura de Cordel. São Paulo: Brasiliense, 2005. 